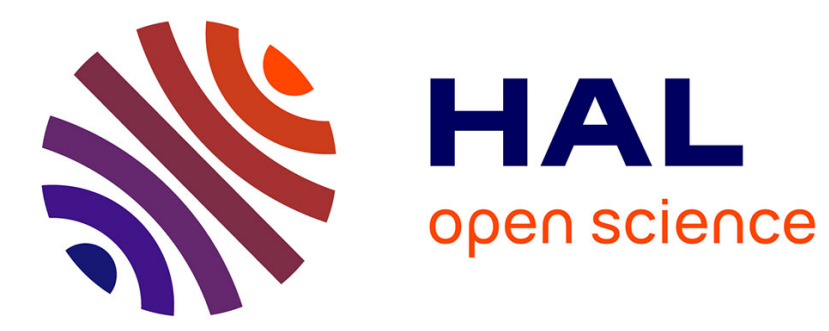

\title{
Nonaxisymmetric Effects for Three-Dimensional Analysis of a Brake
}

Anne Floquet, Marie-christine Baïetto-dubourg

\section{To cite this version:}

Anne Floquet, Marie-christine Baïetto-dubourg. Nonaxisymmetric Effects for Three-Dimensional Analysis of a Brake. Journal of Tribology, 1994, 116 (3), pp.401. 10.1115/1.2928852 . hal-02129076

\section{HAL Id: hal-02129076 https://hal.science/hal-02129076}

Submitted on 15 Jul 2021

HAL is a multi-disciplinary open access archive for the deposit and dissemination of scientific research documents, whether they are published or not. The documents may come from teaching and research institutions in France or abroad, or from public or private research centers.
L'archive ouverte pluridisciplinaire HAL, est destinée au dépôt et à la diffusion de documents scientifiques de niveau recherche, publiés ou non, émanant des établissements d'enseignement et de recherche français ou étrangers, des laboratoires publics ou privés. 


\section{Nonaxisymmetric Effects for Three-Dimensional Analysis of a Brake}

A three-dimensional model of axisymmetric moving solids submitted to nonaxisymmetric transient heat flux conditions is presented in this paper. Temperature fields are obtained using a new hybrid FFT-FEM method that combines Fourier transform techniques and finite element method. A fast Fourier transform algorithm is used which leads to inexpensive computer time. Validation tests are presented. Efficiency of the method is demonstrated.

\author{
A. Floquet \\ Université C. Bernard, \\ Lyon I, \\ 43 Bvd. du 11 Novembre,
}

69622 Villeurbanne Cédex, France

M. C. Dubourg

I.N.S.A.,

Laboratorie de Mécanique des Contacts, URA CNRS 856,

20, Av. A. Einstein,

69621 Villeurbanne Cédex, France

\section{Introduction}

Friction in brake systems depends on many phenomena, but temperature rise is of course the governing factor. Flat frictional surfaces and free contact conditions are essential for good brake performance. Temperature rise induces thermoelastic distortions leading to surface waves.

Lee and Barber (1992) show that if the sliding speeds exceeds a certain critical value instabilities arise leading to the establishment of localized high temperature contact regions, regularly spaced known as hot spots. Hot spots are associated with localized thermal expansions, interfacial pressure peaks and wear. This phenomenon is known as frictionally excited thermoelastic instability or TEI (Barber 1967, 1969). These phenomena can't disappear from one brake application to another. The problem is to compute the evolutions of contact pressure, surface profiles, and surface temperature when two elastic bodies slide on each other. This is a coupled thermoelastic problem (Day, 1987) since the contact pressure will depend on the thermal distortion of the bodies and the amount of frictional heat generation will depend on the contact pressure. A complete brake system analysis must take into account crazing due to severe thermal loadings resulting in alternative compressive and tensile stresses. Further complex contacting surface geometry (groove, pad, ventilation) resulting in stress concentrations may favor surface crack propagation (Dubourg et al., 1992). Crack propagation analysis is therefore necessary as it governs time lift brake systems.

This complete analysis will be achieved in three steps:

The first one, presented in this paper, is concerned with a three-dimensional transient thermal analysis with variable speed effects.

The second one, in preparation, is the thermoelastic analysis of a complete brake system including the presence of pads. The contact problem between pads and disk is solved in terms of temperature and pressure distributions.
The third and last step, will be the thermal crazing analysis.

The model corresponding to the first step is based on anew hybrid method F.F.T.-F.E.M, combining Fourier transform techniques and finite element methods. A Fourier transform is applied with respect to the space variable $\theta$. The originality lies in the use of a fast Fourier transform algorithm which avoids singularity problems and is expensive in computer time. The transformed problem is then classically analyzed with the finite element technique for each frequency considered. Inverse transforms are then performed.

\section{The Thermal Problem: Moving Solid at Variable Speed Under Nonaxisymmetric Transient Heat Condi- tions}

This thermal analysis is often performed using finite element modeling techniques and for economic reasons, the analysis is usually two-dimensional. This simplification implies contact conditions and heat flux transfer independent of $\theta$. This leads to false elastic distortions and unrealistic contact conditions (Floquet, 1989).

A disk or a drum brake system is made in two parts:

A mobile one, geometrically axisymmetric, composed of the disk and the rim; contact conditions correspond to a heat flux which is a function of time and space variables $r$ and $\theta$, the boundary conditions outside the contact zone correspond to convection, radiation, and sometimes to known temperature (wheel axle or rim). The material thermal characteristics are temperature related. The sliding speed and the heat flux are time dependent.

A fixed part, composed of blocks and caliper: the geometry is three dimensional, the sliding speed is nil. The contact and boundary conditions are identical to those defined for the mobile part; the material thermal characteristics are also temperature related.

Classical finite element techniques are very well adapted for the fixed part of brake systems but three-dimensional modeling of the mobile part implies a very refined mesh as numerical instabilities arise when the Peclet number $\mathrm{P}$ is greater than 2 (Kennedy et al., 1984). That corresponds to a disk sliding speed 
$V$ greater than a critical value, $V c$, or to a mesh size $e$ in the sliding direction smaller than:

$$
P=V c^{*} e / 2 D<2 \Leftrightarrow \mathrm{e}<4 D / V c
$$

where $D$ is the material diffusivity. This limit implies reducing the element mesh size according to the sliding speed. That leads for instance to an element size of $1.5 \mu \mathrm{m}$ for an vehicle iron disk $(D=1.510-5 \mathrm{~m} 2 / \mathrm{s})$ and $V=40 \mathrm{~m} / \mathrm{s}$ ! An unreasonable number of elements would thus be required.

A new method -is proposed here to perform a three-dimensional thermal analysis of a moving axisymmetric solid submitted to nonaxisymmetric heat flux conditions (Floquet, 1985). This method combines Fourier integral transform techniques and finite element methods. Transforms are obtained through a fast Fourier Transform algorithm in order to reduce computer time and to avoid numerical singularities.

\section{Description of the F.F.T-F.E.M. Technique}

III.1 Geometry and Boundary Conditions. Any axisymmetric geometry is considered (Fig. 1). Its volume $(V)$ is limited by its surface $(S)$. The symmetric axis is $O Z$. The meridian plane $\Omega$ is bounded by $\Gamma$. The material thermal characteristics are temperature related, except in the $\theta$ direction where the mean value will be used as a reference. The entire surface $S$ is split into three disjoint surfaces S1, S2, and S3. Classical boundary conditions are considered

Prescribed temperature on S1,

Prescribed heat flux on S2,

Natural or forced convection on S3.

Note that the prescribed heat flux on S2 comes from the heat dissipation in the contact zone. In this work, the frictional heat is supposed to enter totally into the disk brake. In the step two of the modeling which will be presented in the future, matching of the thermal contact conditions at the pad/disk interface will be taken into account.

S1 (S2 and S3 too) is partially bounded by $\Gamma$ when $\theta$ varies from 0 to $2 \pi$. No particular conditions are required for initial temperature.

III.2 Theoretical Formulation. The basic concept of the method lies on Fourier transform with respect to the space variable $\theta$. In practice, this is done by the Fast Fourier transform (FFT) technique (Brighman, 1974). The calculation time is considerably reduced and no singularitiy problems are met in the inverse transform. This FFT technique is combined using the Singleton method (Singleton, 1969) which accepts any number of discretization points with respect to the transformed variable.

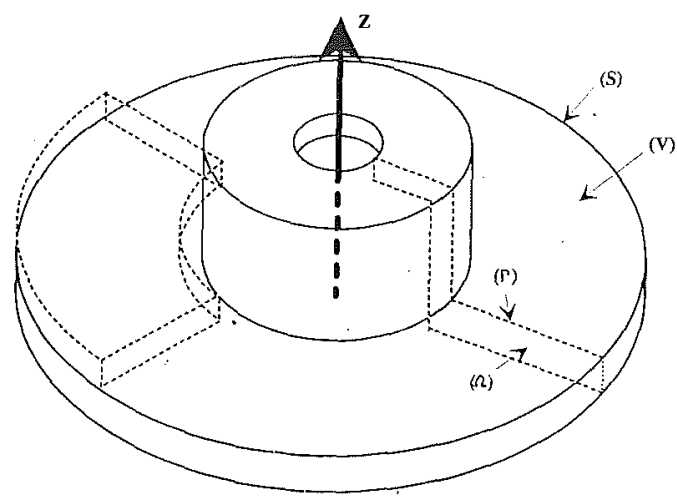

Fig. 1 Brake disk

The heat-conduction equation is given in the cylindrical coordinate system $(r, \theta, z)$ attached to the fixed part.

$\frac{\partial^{2} T}{\partial r^{2}}+\frac{1}{r} \frac{\partial T}{\partial r}+\frac{\partial^{2} T}{\partial z^{2}}+\frac{1}{r^{2}} \frac{\partial^{2} T}{\partial q^{2}}=\frac{1}{D}\left(\frac{\partial T}{\partial t}+w \frac{\partial T}{\partial q}\right)$

Boundary Condition (BC):

$$
\begin{array}{cc}
T(r, q, z, t)=T_{c}(r, q, z, t) & \text { on }\left(\mathrm{S}_{1}\right) \\
k \operatorname{grad} T \cdot \bar{n}=q_{c}(r, q, z, t) & \text { on }\left(\mathrm{S}_{2}\right) \\
-k \operatorname{grad} T \cdot \bar{n}=h\left(T-T_{a}\right) & \text { on }\left(\mathrm{S}_{3}\right) \\
\text { Initial Condition }(\mathrm{IC}): & \\
T(r, q, z, 0)=T_{i}(r, q, z) & \text { at } t=0
\end{array}
$$

$D$ is assumed constant on a volume control element and independent of $\theta$. $h$ takes into account convection and radiation and is a function of both position and time. It is assumed to be constant over a surface element during a time step.

The application of a transform integral to (1) has the effect of removing partial derivatives with respect to the space variable considered from the heat conduction equation and thus of reducing the dimensionality of the problem. The space variable considered here is $\theta$. The Fourier integral transform with respect to the $\theta$ variable for a cyclic function $g(x)$ with a period of $2 \pi$, is defined by $\bar{g}(f)$

$$
\begin{aligned}
\bar{g}(f) & =\int_{0}^{L} g(x) \exp (-2 j \pi f x) d x \\
\text { with } f & =\frac{n}{L}, n \in N ; j \text { is a pure imaginary number }
\end{aligned}
$$

The integral transform of the system (1) by the application of the transform (2) yields

\section{Nomenclature}

$$
\begin{aligned}
C= & \text { thermal capacity } \\
D= & \text { thermal diffusivity } \\
f= & \text { frequency } f=n / \\
h= & \text { heat thermal coef- } \\
& \text { ficient } \\
k= & \text { thermal conductiv- } \\
& \text { ity } \\
q_{c}= & \text { known heat flux: } \\
& \text { boundary condi- } \\
& \text { tion on S2 } \\
n= & \text { natural integer } \\
\bar{n}= & \text { outer normal } \\
= & \text { body surface } \\
t= & \text { time }
\end{aligned}
$$

$T=$ temperature field

$T_{a}=$ ambient temperature

$T_{c}=$ known temperature: boundary condition on $\mathrm{S} 1$

$T_{i}=$ initial temperature field

$\bar{T}=$ Fourier transform of $T$ versus $\theta$

$\overline{T_{a}}=$ Fourier transform of $T_{a}$ versus $\theta$

$\overline{T_{c}}=$ Fourier transform of $T_{c}$ versus $\theta$

$\bar{T}_{i}=$ Fourier transform of $T_{i}$ versus $\theta$

$$
\begin{aligned}
T^{l}, q^{R} & =\text { real part of } \bar{T} \text { and } \\
T^{l}, q^{l} & =\frac{\text { imaginary part of }}{\bar{T} \text { and } q} \\
r, \theta, z & =\text { cylindrical coordi- } \\
& \text { nates } \\
V & =\text { body volume } \\
W & =\text { test function } \\
\alpha & =2 \pi f \\
\beta & =2 \pi f \omega \\
\rho & =\text { specific mass } \\
\Gamma 2 \cup \Gamma 3= & \Omega \text { boundary } \\
\omega & =\text { angular velocity } \\
\Omega & =\text { meridian plane of } \\
& \text { the body }
\end{aligned}
$$




$$
\begin{aligned}
& \frac{\partial^{2} \bar{T}}{\partial r^{2}}+\frac{1}{r} \frac{\partial \bar{T}}{\partial r}+\frac{\partial^{2} \bar{T}}{\partial z^{2}}-\left(\frac{\boldsymbol{\alpha}^{2}}{r^{2}}+j \frac{\beta}{D}\right) \bar{T}=\frac{1}{D} \frac{\partial \bar{T}}{\partial t} \quad \text { on }(\Omega) \\
& B C: \bar{T}(r, z, t)=\bar{T}_{c}(r, z, t) \quad \text { on }\left(\Gamma_{1}\right) \\
& k \overline{\operatorname{grad} T} \cdot \vec{n}=\bar{q}_{c}(r, z, t) \quad \text { on }\left(\mathrm{\Gamma}_{2}\right) \\
& -k \overline{\operatorname{grad} T} \cdot \vec{n}=h\left(\bar{T}-\bar{T}_{a}\right) \quad \text { on }\left(\mathrm{I}_{3}\right) \\
& \text { IC: } \bar{T}(r, z, 0)=\bar{T}_{i}(r, z, 0) \\
& \text { With } \quad \alpha=2 \pi f \\
& \beta=2 \pi f \omega \\
& f=n / 2 \pi
\end{aligned}
$$

where $\overline{T c}, \overline{q c}, \bar{T} a$, and $\bar{T} i$ are respectively, the transformed boundary conditions in terms of temperature, heat flux and environment and initial temperatures. These are known quantities. Note that the variable $\theta$ has been transformed into a discrete parameter. The domain and the bounded surfaces are respectively transformed into $\Omega, \Gamma 1, \Gamma 2$, and $\Gamma 3$.

Since the speed effect has been removed from the problem, the finite element technique can be applied directly. Considering a test function $W(r, z), r, z \in(\Omega)$ and applying the Green formula to (3), the weak formulation of the problem is:

$$
\begin{aligned}
& \int_{\Omega} \overline{\operatorname{grad}} \bar{T} \cdot \overline{\operatorname{grad}} W d \Omega+\int_{\Omega} \frac{1}{r} \frac{\partial \bar{T}}{\partial r} W d \Omega-\alpha^{2} \int_{\Omega} \frac{\bar{T}}{2} W d \Omega \\
& j \beta \int_{n} \frac{\bar{T} W}{D} d \Omega+\int_{\Gamma_{2}} \frac{\bar{q}_{c}}{k} W d \Gamma-\int_{\Gamma_{3}} \frac{h}{k}\left(\bar{T}-\bar{T}_{a}\right) W d \Gamma=\int_{\Omega} \frac{1}{D} \frac{\partial T}{\partial t} d \Omega
\end{aligned}
$$

with: $\bar{T}(r, z, t)=\bar{T}_{c}(r, z, t)$ on $\Gamma_{1}$

$$
\bar{T}(r, z, 0)=\bar{T}_{i}(r, z, 0) \text { on } \Omega \text { at } t=0
$$

$\bar{T}_{c}, \bar{q}_{c}, \bar{T}$ and $\bar{T}_{i}$ are complex quantities. Real and imaginary parts are separated. The notations employed are: $\bar{T}=T^{R}+$ $j T^{I}$. This leads to:

$$
\begin{aligned}
& \int_{\Omega} \frac{1}{D} \frac{\partial T^{R}}{\partial t} W d \Omega+\int_{\Omega} \overline{\operatorname{grad}} T^{R} \cdot \overline{\operatorname{grad}} W d \Omega-\int_{\Omega} \frac{1}{r} \frac{\partial T^{R}}{\partial r} W d \Omega \\
+ & \alpha^{2} \int_{\Omega} \frac{T^{R}}{r^{2}} W d \Omega-\beta \int_{\Omega} \frac{T^{l}}{D} W d \Omega-\int_{\Gamma_{2}} \frac{q_{c}^{R}}{k} W d \Gamma+\int_{\Gamma_{3}} \frac{h}{k}\left(T^{R}-T_{a}^{R}\right) W d \Gamma=0 \\
& \int_{\Omega} \frac{1}{D} \frac{\partial T^{I}}{\partial t} W d \Omega+\int_{\Omega} \overline{\operatorname{grad}} T^{R} \cdot \operatorname{grad} W d \Omega-\int_{\Omega} \frac{1}{r} \frac{\partial T^{R}}{\partial r} W d \Omega \\
+ & \alpha^{2} \int_{\Omega} \frac{T^{I}}{r^{2}} W d \Omega+\beta \int_{\Omega} \frac{T^{R}}{D} W d \Omega-\int_{\Omega_{2}} \frac{\underline{q}_{c}^{I}}{k} W d \Gamma+\int_{\Gamma_{3}} \frac{h}{k}\left(T^{I}-T_{a}^{I}\right) W d \Gamma=0
\end{aligned}
$$

$T(r, \theta, z)$

$$
=-\frac{q_{0}}{k} \sum_{m=1}^{\infty} \frac{-(1)^{m}}{\lambda^{2}}\left[1-\exp \left(-D \lambda^{2} t\right)\right] \sin \left(\beta_{m} z\right) \cos (1 \theta)
$$

This transformed system is then solved using two-dimensional finite element techniques. Two degrees of freedom are considered by node (real and imaginary part). (5) is transformed classically following the finite element technique (Dhatt and Thouzot, 1981) into:

$$
A \frac{d \bar{T}}{d \bar{t}}+B \bar{T}=F
$$

This differential system may be solved by implicit or explicit classical methods (Euler, Runge Kutta, Prediction-Correction). The system must be solved for each frequency $f$. Heat transfer phenomena in moving media submitted to periodic oscillations behaves like a low pass frequency filter. As it will be demonstrated in $\S V$ with practical tests, the twenty first frequencies are sufficeint for a correct simulation.

The FFT-FEM method described above can simulate transient heat transfer in 3-D axisymmetric moving solves for variable speed and nonaxisymmetric transient heat flux. Further, thermal material characteristics $(D, k)$ can be temperature related. In order to validate this technique, comparisons were

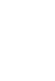

performed on a simple geometric configuration under various solutions exist.

\section{Test Cases} Anted in Fig. 2. This region is initially at a nil temperature. but dependent on $\theta$, is applied at the boundary $z=e$, and the side boundaries are insulated. The height $e$ is equals to 0.09 $\mathrm{m}$. The geometrical conditions are identical for all tests as well the material properties considered, respectively $h=100 \mathrm{~W} /$

${ }^{\circ} \mathrm{C}, k=50 \mathrm{~W} / \mathrm{m}^{\circ} \mathrm{C}, \rho=7800 \mathrm{~kg} / \mathrm{m}^{3}, C=500 \mathrm{~J} / \mathrm{kg}^{\circ} \mathrm{C}$. analytical solution to the most complex one. Changes concern terms of speed and heat flux. $q_{0} \cos (1 \theta)$ with $q_{0}=$ constant $=10^{6} \mathrm{~W} / \mathrm{m}^{2}$

is assumed to be small enough for $T$ to be independent of $r$. The analytical solution of this problem is (Oziski, 1980): 


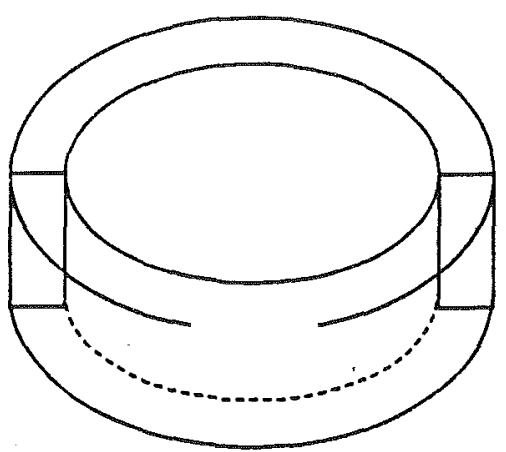

Fig. 2(a) Test geometry

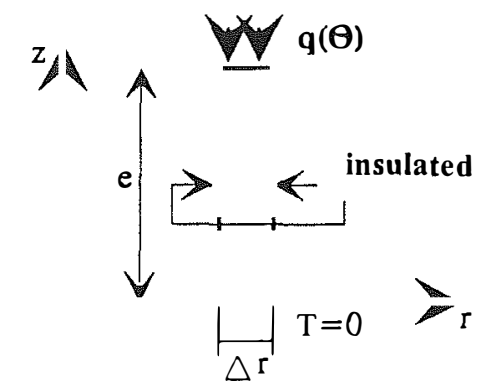

Fig. 2(b) Meridian plane of geometry test

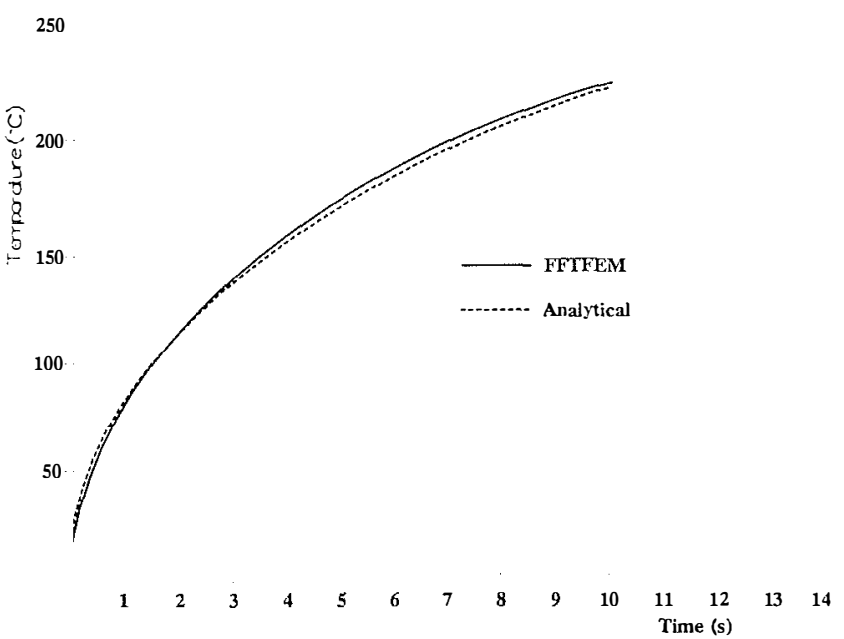

Fig. 3 Temperature field versus time for $z=$ e end $\theta=0$ heat flux $q$ $=10^{6} \cos (10 \theta) \mathrm{W} / \mathrm{m}^{2}$

$-z$ for $t=1 \mathrm{~s}$ and $10 \mathrm{~s}$ and for the angle $\theta=0$,

$-t$ for $z=0.9$ and $z=e$ and for the angle $\theta=0$,

$-\theta$ for $t=1 \mathrm{~s}$ and $t=10 \mathrm{~s}$ and $z=0.9$ and $z=e$.

are presented in Figs. 5, 6, and 7, respectively. Note that in Fig. 6 for $t=0$, the slope of the curve is nil for $z=0.9 e$ and different from 0 for $z=e$.

Small oscillations or GIBBS phenomena are due to the limitation of the number of frequencies considered here for the calculation (only 16) (Colin et al., 1988). It has no consequence as Fourier transforms converge in the mean. Further, a comparison between the temperature obtained by considering 360 frequencies instead of 16 has been performed: the difference

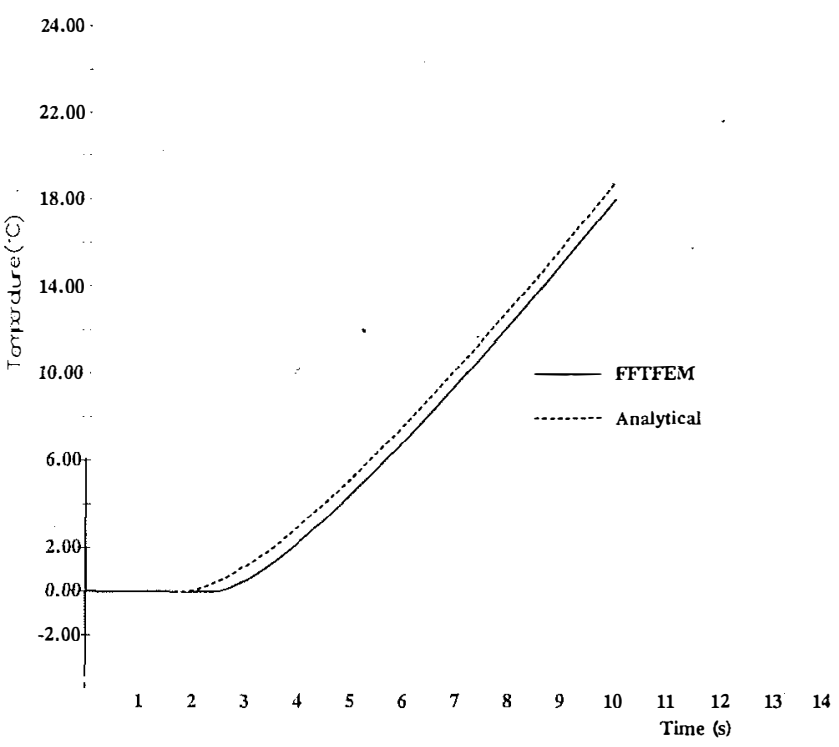

Fig. 4 Temperature field versus time for $z=.75$ e end $\theta=0$ heat flux $q=10^{6} \cos (10 \theta) \mathrm{W} / \mathrm{m}^{2}$

290.00

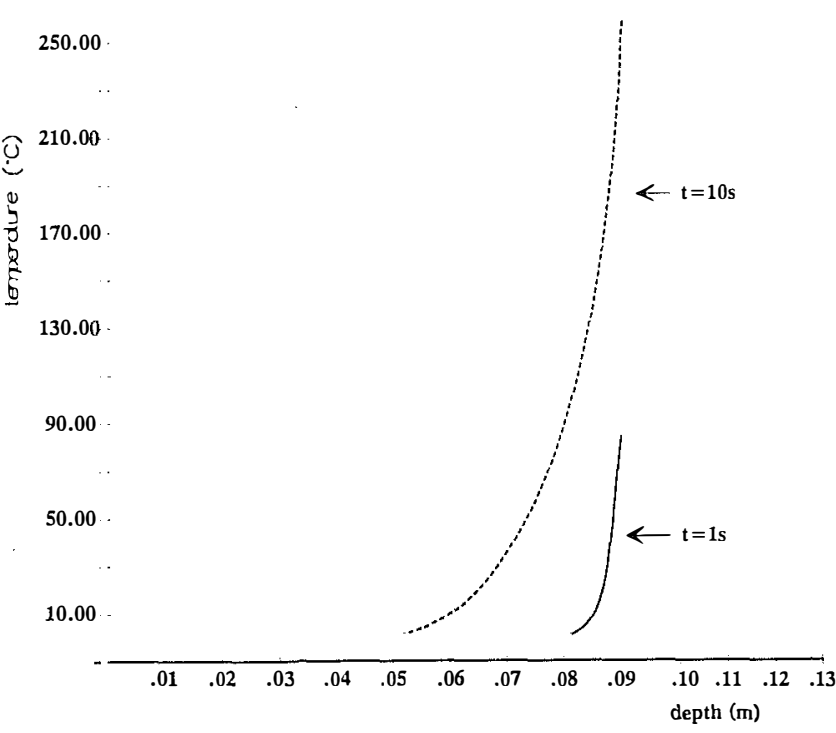

Fig. 5 Temperature field versus depth for $\theta=0$ and different times

is equal to $2.82^{\circ} \mathrm{C}$ with respect to the maximum value of $255^{\circ} \mathrm{C}$, i.e., a difference of 1.3 percent.

IV.3 Constant Speed and Constant Heat Flux Localized on a Small Region of the Ring. The heat-flux conditions are identical to those defined in IV.2. The velocity is now different from zero: it is assumed constant and equal to $\omega=20 / \mathrm{s}$. Temperature variations versus:

$-t$ for the angle $\theta=0$ and for $z=e$ and $z=0.9 e$,

$-\theta$ for $t=1 \mathrm{~s}$ and $t=10 \mathrm{~s}$ and for $z-0.9 e$ and $z=e$, are presented in Figs. 8 and 9, respectively.

Comparison between temperature variations versus $z$ for $t$ $=1 \mathrm{~s}$ and $10 \mathrm{~s}$ and for the angle $\theta=0$, obtained in that case and for the static one is shown in Fig. 10. In both cases, a temperature softening effect dependent on $z$ (the depth) is noted. It is more important in the speed case.

The velocity $V$ causes a drop in maximum temperature as cold material is brought under the heat source, as noted earlier 


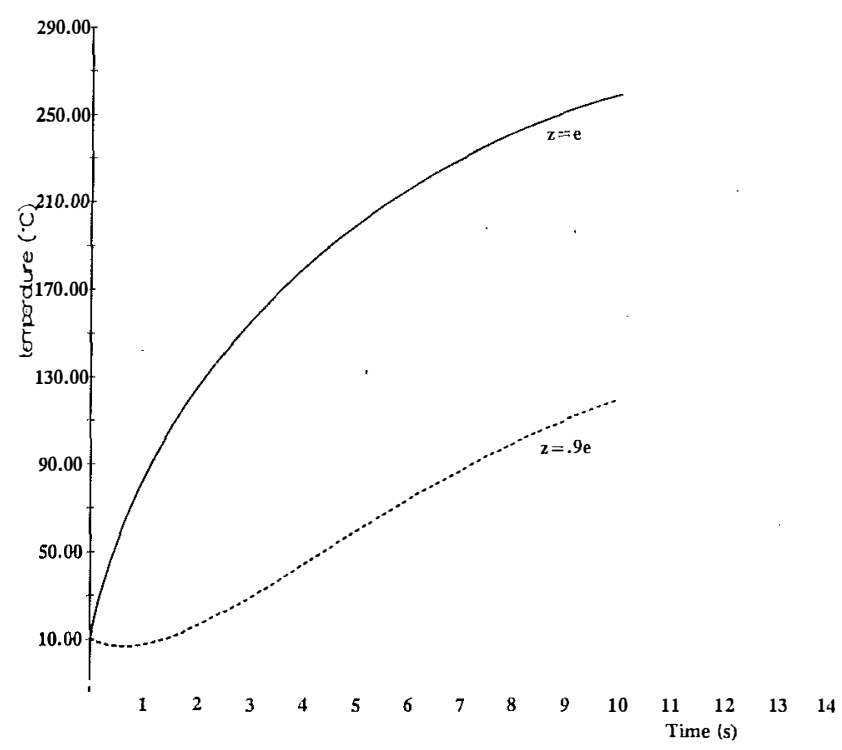

Fig. 6 Temperature field versus time for $\theta=0$ and different depths heat flux $q=q_{0} \cos [5 / 2(\theta-\pi)] \theta c[4 \pi / 5,6 \pi / 5], q=0$ elswhere

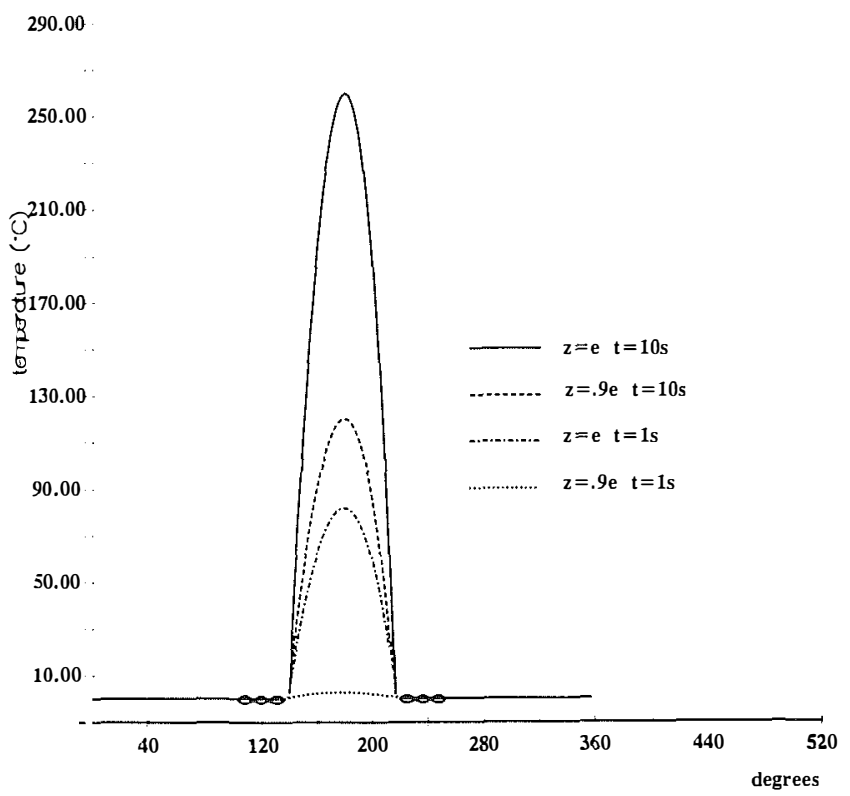

Fig. 7 Temperature field versus $\theta$ for different times and depths

(Colin et al., 1988), (Leroy et al., 1989, 1990). Further, the temperature increase concerned a wider strip of material for the static case than for the moving one (Floquet A., and Ménard D., 1986).

IV.4 Variable Speed and Heat Flux. Speed and heat flux decrease linearly versus time down to zero, as in a braking operation. Initial values are respectively equal to $20 / \mathrm{s}$ and $10^{6}$ $\mathrm{W} / \mathrm{m}^{2}$. The operation lasts to $t_{0}=6 \mathrm{~s}$. Figures show:

The temperature variations for the angle $\theta=0$ and for $z$ $=0.9 e$ and $z=e$ in Fig. 11; two periods are observed:

$t<6 \mathrm{~s}$ : it corresponds to the braking period: the temperature increases rapidly at the surfaces $(z=e)$; at $z=0.9 e$ the maximum value is smaller and shifted forward.

$t>6 \mathrm{~s}$ : no more heat flux is applied: it corresponds to the slope break for both curves. Again this phenomenon is observed later in time at $z=0.9 e$. Note also that for $z=0.9 e$, the temperature continues to increase during a short period, before decreasing due to the redistribution of the temperature field in the disk.

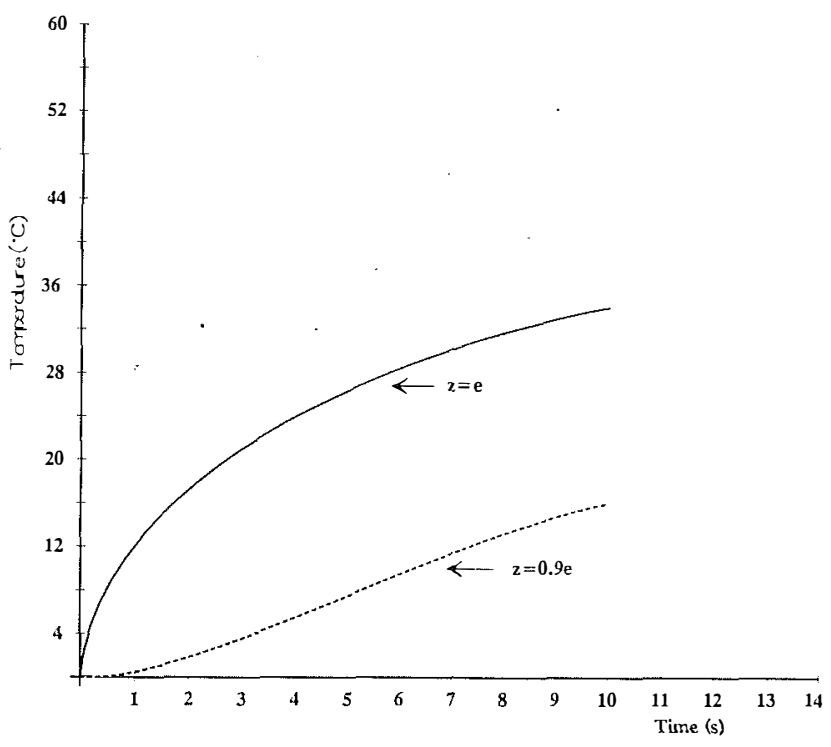

Fig. 8 Temperature field versus time for $z=\mathrm{e}$ and $z=.9 e$ with constant speed $\omega=20 / \mathrm{s}$

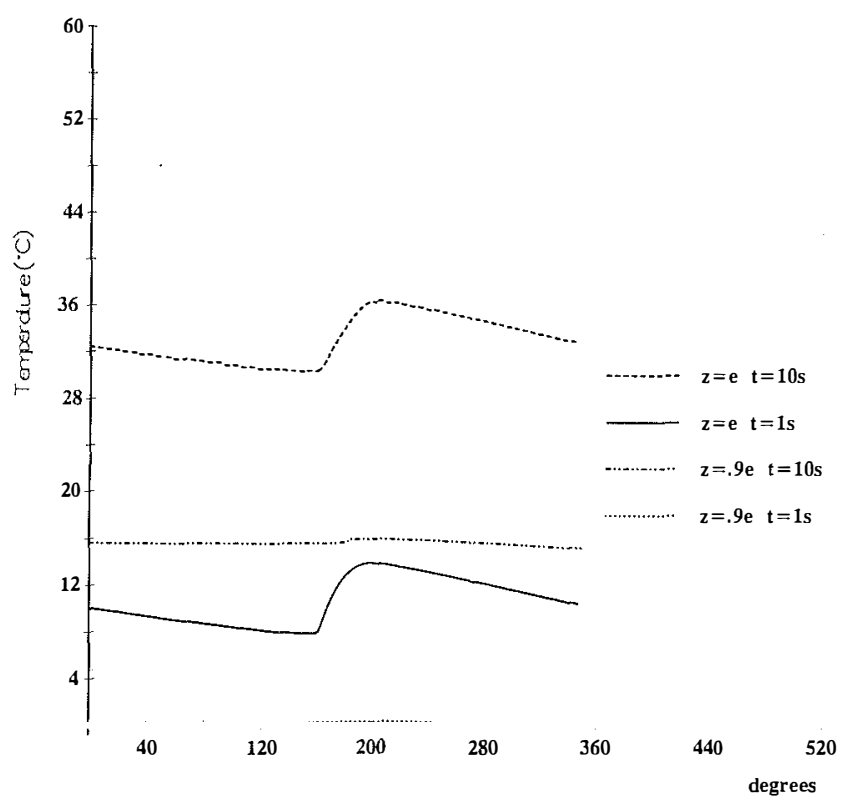

Fig. 9 Temperature field versus $\theta$ with constant speed $\omega=20 / \mathrm{s}$

The temperature variations versus the angle $\theta$ for $t=1 \mathrm{~s}$ and $10 \mathrm{~s}$ and for $z=e$ and $0.9 e$ in Fig. 12 .

This case is very close to conditions encountered in a braking operation. The main difference comes from curvature effects which are not taken into account here, but is it not a limitation of the method at this simple geometrical configuration was retained for comparison with analytical solutions existing for the first test.

\section{General Case}

A 3-D simulation, based upon a vehicle disk brake, takes into account temperature variations on $r, \theta, z$. The geometry, the dimensions and the mesh of the meridian plane are presented in Fig. 13. A cartesian coordinate system $(0, x, y, z)$ is considered. 225 nodes are considered with 2 deg of freedom per node. The running conditions in terms of flux, speed and braking time are identical to those considered in §IV.4. Convection is considered on $\mathrm{S} 3=\mathrm{S}$. The heat flux $q$, constant versus 


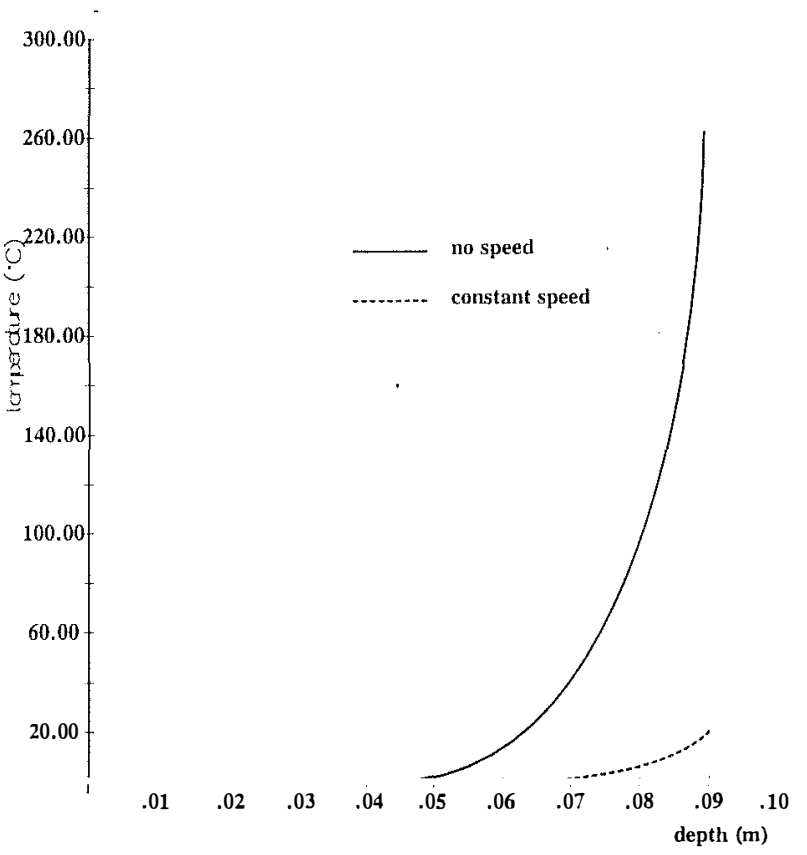

Fig. 10 Temperature field versus depth at $t=10 \mathrm{~s}$ for null and constant speed

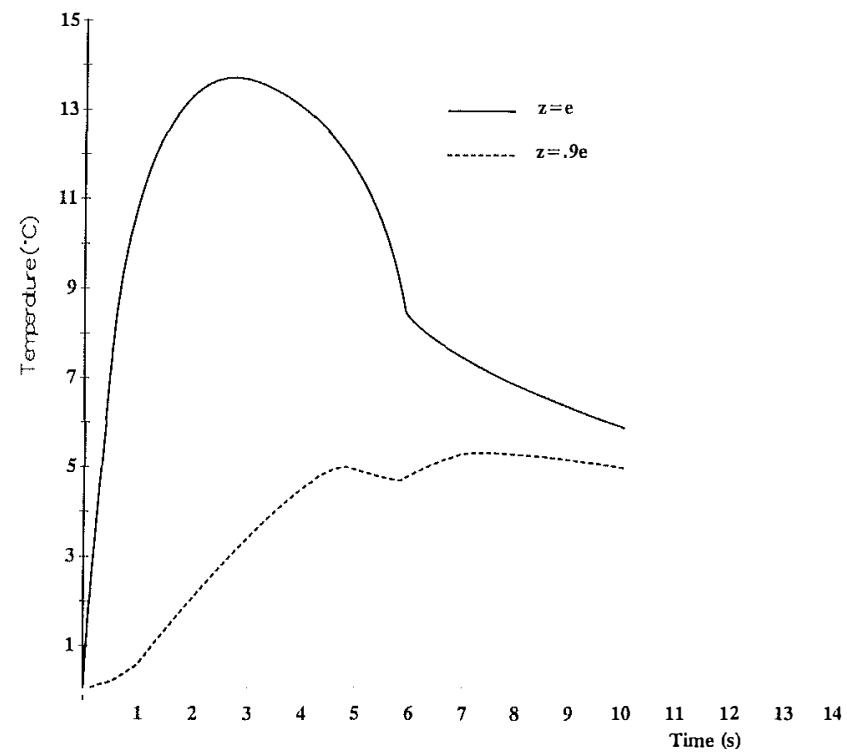

Fig. 11 Temperature field versus time with decreasing speed from $\omega$ $=20 / \mathrm{s}$ to 0 in 6 seconds

$r$, variables versus $\theta$ and time, is imposed on 2 symmetric zones, corresponding to both pads: S2 is a $73 \mathrm{deg}$ arc length sector. The temperature field calculated on the surface $S^{\prime}$, defined in Fig. 13, is shown in Fig. 14 at $t=4 \mathrm{~s}$. Obviously the temperature field is higher in the $\mathrm{S} 2$ region.

VI Computer Time. The computer time required for modeling a three-dimensional geometrical axisymmetric problem submitted to nonaxisymmetric conditions like transient heat transfer and variable speed, is equivalent with the FFTFEM technique to the time required for a two-dimensional finite element modeling with two degrees of freedom by node for each frequency considered. But as noted above, only the lowest frequencies are taken into account and 20 is generally sufficient in most cases. Computer time is therefore very small when compared to a three dimensional finite element analysis

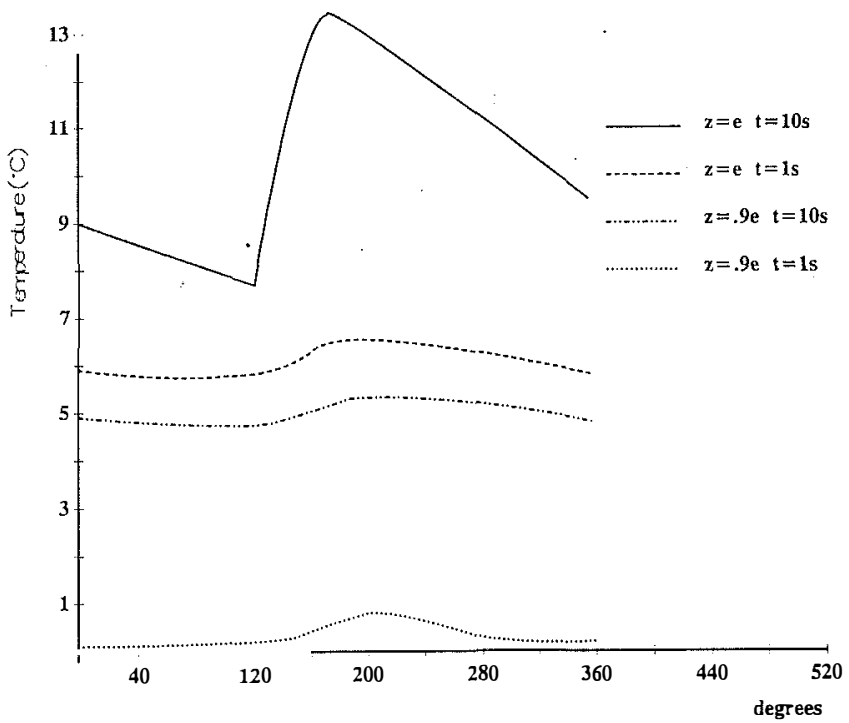

Fig. 12 Temperature field versus $\theta$ with decreasing speed from $\omega=$ $20 / \mathrm{s}$ to 0 in 6 seconds

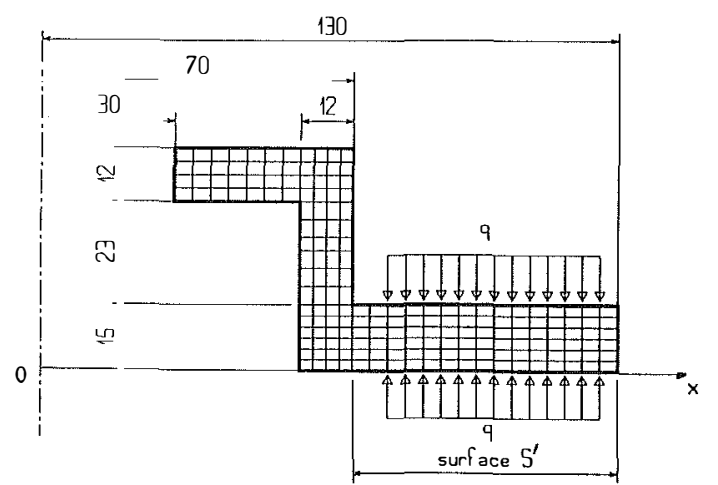

Fig. 13 Disk geometry

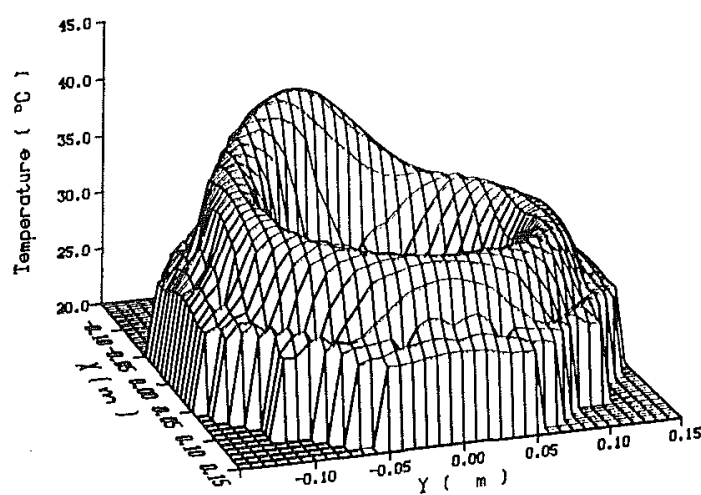

Fig. 14 Temperature distribution on surface $S$ at $t=4 \mathrm{~s}$

with hexadedral elements of equivalent size in the $\theta$ direction with respect to element size in the $(r, z)$ plane. For instance, the case treated in $\& \mathrm{~V}$. with 225 nodes in the meridian plane with two degrees of freedom per node takes only 8 seconds of computer time on a 12 specmark computer for a time step for a 3-D calculation according to the FFT-FEM method. A classical 3-D thermal analysis performed with the finite element code NASTRAN, on the same case,but with no speed effects, and a mesh of 225 nodes with 1 degree of freedom per node 
in the meridian plane and 72 elements in the $\theta$ direction (five deg angle element), i.e., 16200 nodes, takes 30 minutes of computer time on the same computer for a time step. The FFT.FEM method is 225 times faster! Taking into account speed effects requiring very refined mesh size in the sliding direction, thus finer mesh than those considered above will be necessary: the classical finite elemerit techniques are unsuitable for that case.

\section{Conclusion}

This original technique F.F.T.-F.E.M. combines quickness and accuracy of the transform techniques with the finite element method's flexibility. It is used here to analyze three dimensional axisymmetric time dependent problems, such as brake systems. Numerical instabilities that arise in classical finite element analysis when the sliding speed is important are completely removed here. Results obtained are of good quality for small computer times.

The application of this technique to brake systems is straightforward. Stress fields can then be obtained with a classical elastic analysis. This information (temperature and stresses) in every point of the material are initial data for the analysis of fatigue crack behavior.

This FFT-FEM technique is part of a global research project of complete modeling and simulation of the thermomechanical behavior of braking operations.

\section{Acknowledgments}

The financial support of Renault Vehicules Industriels is greatly acknowledged.

\section{References}

Barber, J. R., 1967, 'The Influence of Thermal Expansion on the Friction and Wear Process," Wear, Vol. 10, pp. 155-159.
Barber, J. R., 1969, "Thermoelastic Instabilities in the Sliding of Conforming Solids," Proc. Roy. Soc., Series A312, pp. 381-394.

Brigham, E. O., 1974, The Fast Fourier Transform, Prentice Hall, Englewood Cliffs, N.J.

Colin, F., Floquet, A., 1986, "Combination of Finite Element and Integral Transform Techniques in a Heat Conduction Quasi-Static Problem," International Journal of Numerical Methods in Engineering, Vol. 23, p. 13-23.

Colin, F., Floquet, A., Play, D., 1988, "Thermal Contact Simulation in 2D and 3-D Mechanisms," ASME Journal of Tribology, Vol. 110, No. 2, pp. 247-252.

Day, A. J., 1988, "An Analysis of Speed, Temperature and Performance Characteristics of Automotive Drum Brakes," ASME Journal of Tribology, Vol. 110, pp. 299-305.

Day, A. J., Tirovic, M., and Newcomb, T. P., 1991, "Thermal Effects and Pressure Distributions in Brakes," Proc. Instn. Mech Engrs., Vol. 205, pp. 199205.

Dhatt, G., and Touzot, G., "Une Présentation de la méthode des éléments finies," Maloine S. a., Paris, 1981, p. 542.

Dubourg, M. C., and Fouquet, A., "Thermomechanical Fatigue Approach for Brake System Analysis," Eurotrib '93, to be published.

Floquet, A., 1985, “Lest Températures éclairs en systéme multicouche," EU-

ROTRIB, Lyon, Session DII; Moynes d'investigation nouveaux Méthodes de Calcul, Vol. I, pp. 4.2.1-4.2.10.

Floquet, A., and Ménard, D., 1986, "Calcul des températures de surface dans un systéme de freins à disque," 2ème congrès mondial des engrenages, Vol. 1, pp. 171-180.

Floquet, A., 1989, “Modélisation Thermique Bidimensionnelle des instabilités du freinage," Contrat Régie Renault H3-13-502, 225 pp.

Kennedy, F. E., Colin, F., Floquet, A., and Glovsky, R., 1984, "Improved Techniques for Finite Element Analysis of Sliding Surface Temperatures, " $N u$ merical and Experimental Methods Applied to Tribology, D. Dowson, et al., eds., Westbury House, pp. 138-150.

Lee, K., and Barber, J. R., "Frictionally-Exited Thermoelastic Instability in Automative Disk Brakes," To be published in ASME Journal OF Tribology. Leroy, J.-M., Floquet, A.,d Villechaise, B., 1989, "Thermomechanical Behavior of Multilayered Media: Theory," ASME Journal of Tribology, Vol. 111, No. 3, pp. 538-544.

Leroy, J.-M., Floquet, A., and Villechaise, B., 1990, "Thermomechanical Behavior of Multilayered Media: Results," ASME Journal OF TRIBOLOGY, Vol. 112, No. 2, pp. 317-323.

Ozisik, N. M., Heat Conduction, Wiley, New York, 1980, p. 687.

Singleton, P. C., 1969, "An Algorithm for Computing the Mixed Radix Fast Fourier Transform," IEEE Transaction on Audio and Electroacoustics, Vol. 17, No. 2, pp. 93-103. 